\title{
INTERRUPÇÃO DA GRAVIDEZ DE FETO ANENCÉFALO: APLICAÇÃO DO PRINCÍPIO DA DERROTABILIDADE DA NORMA PARA GARANTIA DO DIREITO À INTEGRIDADE PSÍQUICA DA PERSONALIDADE DA GESTANTE
}

\author{
Eloísa Baliscki Romeira ${ }^{1}$ \\ Alessandro Severino Valler Zenni ${ }^{2}$
}

\begin{abstract}
Resumo
A derrotabilidade propõe uma forma de interpretação a fim de resolver problemas jurídicos relativos à aplicação do direito em diferentes contextos fáticos e jurídicos, cuja aplicação integral e literal da mensagem do direito positivo, ainda que presentes os requisitos necessários e suficiente para aplicação, implica em um resultado incompatível. Nesse caso, faz-se necessário o reconhecimento de uma exceção implícita. O objetivo do presente trabalho é demonstrar a relação entre o princípio da derrotabilidade da norma e o direito à integridade psíquica da personalidade da gestante nos casos de feto anencéfalo, à luz da ADPF n ${ }^{\circ} 54$. Para tanto, a pesquisa adotará o método hipotético-dedutivo e a metodologia de revisão bibliográfica de livros e artigos sobre o assunto. Conclui-se na necessidade de afastar a tipificação penal do crime de aborto nos casos de fetos anencéfalo para garantia do direito à integridade psíquica da personalidade da gestante, a fim de promover a segurança humana em um estado democrático.
\end{abstract}

\section{Palavras-chave}

Direitos da Personalidade; Feto Anencéfalo; Integridade Psíquica; Interrupção da Gravidez; Princípio da Derrotabilidade.

\begin{abstract}
Defeasibility offers a form of interpretation in order to solve legal problems related to the application of the law in different factual and legal contexts, whose full and literal application of the message of positive law, even it is present the necessary requirements for application, implications in a incompatible result. In this case, it is necessary to recognize an implicit exception. The objective of the present work is demonstrate the relationship between the principle of defeat of the norm and the right to psychic integrity of the personality of the pregnant woman in cases of anencephalic fetus, in the light of ADPF $n^{\circ} 54$. Therefore, the research will adopt the hypothetical-deductive method and the methodology for bibliographic review of books and articles on the subject. It concludes that there is a need to remove the criminal classification of the crime of abortion in cases of anencephalic fetuses in order to guarantee the right to psychological integrity of the pregnant woman's personality, in order to promote human security in a democratic state.
\end{abstract}

\footnotetext{
${ }^{1}$ Mestranda no Programa de Pós-Graduação em Ciências Jurídicas pela Universidade Cesumar (UniCesumar). Pós-graduanda em Direito Constitucional pelo Damásio. Pós-graduanda em Neurolaw pela Escola da Magistratura Federal do Paraná (ESMAFE-PR). Bolsista do Programa de Pós-Graduação em Ciência Jurídicas (UniCesumar). Graduada em Direito pela Universidade Estadual de Maringá (U.E.M.). Integrante do Grupo de Pesquisa: "Constitucionalização do Direito privado, obrigações, responsabilidade civil, consumidor e direitos da personalidade". Advogada. E-mail: elo_baliscki@hotmail.com. Maringá-PR, Brasil.

2 Pós-Doutor em Direito pela Universidade de Lisboa (Portugal). Doutor em Direito pela Pontifícia Universidade Católica de São Paulo - PUC/SP.
} 


\section{Keyword}

Personality Rights; Anencephalic Fetus; Psychic Integrity; Termination of Pregnancy; Principle of Defeatability.

\section{INTRODUÇÃO}

As sociedades são fundamentalmente complexas, sobretudo pela absoluta impossibilidade de previsão de todas as formas de ação de um ser humano e seus decorrentes reflexos no mundo jurídicos.

A segurança jurídica não é garantida com a positivação. Como se não bastasse a complexidade do ser humano e da sociedade, a linguagem também é uma barreira para a compreensão e correta conceituação dos termos jurídicos pelos legisladores. A indeterminação da linguagem e a impossibilidade de previsão anterior de todas as particularidades possíveis para a resolução de um caso acarreta no necessário exercício de função atípica de legislador pelos tribunais.

Basta observar a prática e o cotidiano dos advogados, juízes e promotores, o fenômeno cotidiano das defesa de soluções excepcionais a determinado caso concreto, quando verificada a não-aplicação do direito positivo, mesmo estando presentes os seus requisitos necessários e suficientes. Assim, consciente ou inconscientemente, argumentam por uma resposta diversa da oferecida pelo legislador. Nesse contexto, sugere-se a Teoria da Derrotabilidade de maneira a dar conformidade jurídica a casos difíceis, fronteiriços, obviamente não previstos ou não adequados socialmente em face das mudanças sociais.

A derrotabilidade propõe excepcionar a incidência de uma norma para garantir um resultado compatível ao ordenamento jurídico, ou seja, apresenta uma forma de interpretação a fim de resolver problemas jurídicos relativos à aplicação do direito em diferentes contextos fáticos e forenses, cuja aplicação integral e literal da mensagem do direito positivo, ainda que presentes os requisitos necessários e suficientes para aplicação, implica em um resultado incompatível. Nesse caso, faz-se necessário o reconhecimento de uma exceção implícita.

Estudioso do assunto, Richard L. A. Hart, em sua obra The Ascription of Responsibility and Rights, de 1949, tornou-se um dos principais expoentes em trazer o termo para aplicação no âmbito da Filosofia do Direito, utilizando-o para qualificar ou simbolizar o caráter derrotável dos conceitos jurídico. 
No Brasil, o Supremo Tribunal Federal reconheceu, na ADPF n ${ }^{\circ} 54$, a possibilidade da interrupção da gravidez de feto anencéfalo, que, apesar de não taxativamente mencionada no julgado a aplicação da teoria da derrotabilidade, tornou-se o principal exemplo no ordenamento jurídico brasileiro. Implicitamente, utilizou-se desse mecanismo de interpretação para preservar a integridade psíquica da gestante, componente da sua saúde e da personalidade da pessoa. A decisão é um reflexo da democracia para garantia da segurança humana, por acatar aclamações de mães durante décadas que bravamente passaram por uma gestação de alto risco, grave impacto psicológico e deram origem a um bebê anencéfalo que, se nascem com vida, $99 \%$ morrem logo após o parto e os demais sobrevivem por poucos dias ou meses.

Assim, este trabalho tem por objetivo demonstrar a necessidade da aplicação do princípio da derrotabilidade para garantir o direito à integridade psíquica que é um direito da personalidade da gestante. Para tanto, utilizando-se do método hipotético-dedutivo, fundamentado em revisão bibliográfica e discussão em três tópicos. Primeiramente, discorrerse-á acerca do Princípio da Derrotabilidade, para melhor compreensão do assunto. Em seguida, demonstrar-se-á a integridade psíquica como um componente da personalidade humana e suas implicações em uma gestante de feto anencéfalo. Por fim, analisar-se-á a Arguição de Preceito Fundamental $n^{\circ}$ 54, que julgou a possibilidade de interrupção da gravidez de feto anencéfalo.

A relevância da pesquisa é justificada diante do valor da saúde mental que não pode ser sonegado, essencialmente quando se refere a mulheres gestantes, cuja condição é a mais nobre da existência humana. Não se pode ignorar, ainda, o risco real à vida da gestante, e a interrupção da gravidez pode assegurar a segurança humana.

Em tempos em que discursos autoritários e conservadores infelizmente ganham destaque, vale reforçar a importância da democracia para uma convivência pacífica e sadia. A mencionada ADPF torna-se um exemplo de que a reivindicação de parte da sociedade deve ser ouvida e prudencialmente decidida, a fim de garantir exigências sociais que são dinâmicas, mas a atualização instantânea das previsões legislativas são inviáveis pela burocracia e pelo jogo das forças sociais antagônicas.

\section{O PRINCÍPIO DA DERROTABILIDADE E SUA TÍMIDA APLICAÇÃO NO ORDENAMENTO JURÍDICO BRASILEIRO}


O princípio que será aqui estudado não foi cunhado no Brasil, por isso, necessário os esclarecimentos acerca dos termos utilizados pelos preceituadores da ideia de derrotabilidade no sistema jurídico. O termo defeasibility é um termo inglês com tradução para derrotabilidade ou superabilidade, utilizado nas áreas que estudam a relação regra/exceção, como a Lógica, Epistemologia e a Filosofia.

A doutrina diverge com relação ao alvo da derrotabilidade, podendo ser: a) normativa (regra e princípios); b) regras jurídicas; c) princípios jurídicos; d) raciocínio jurídico; e d) conceitos jurídicos.

Um dos principais nomes no estudo do Princípio da Derrotabilidade é o filósofo britânico do direito Richard L. A. Hart. Para o autor de The Ascription of Responsibility and Rights (1949), a derrotabilidade não se caracterizaria como uma nova categoria jurídica, mas sim um fenômeno empírico verificável, cujo principal objetivo é demonstrar que a principal função dos conceitos na linguagem ordinária e na jurídica não é de descrever coisas, eventos ou pessoas, ou qualquer outra coisa, nem suscitar sentimentos ou emoções, mas sim de fazer coisas como reivindicar direitos ("Este é meu"), reconhecer direitos quando reivindicados por outra pessoa ("muito bem, isso é seu"), atribuir direitos reivindicados ou não ("este é dele"), direito de transferência ("este agora é seu") e também admitir, atribuir ou fazer acusações de responsabilidade (“eu fiz", “ele fez”, "você faz”) (HART, 1949, p. 171).

Eu outras palavras, Hart defendia que a principal função dos conceitos na linguagem não seria descritiva (no inglês, descriptive), mas sim atributiva (no inglês, ascriptive) de responsabilidade e de direitos, cabendo ao juízes, com auxílio dos critérios de interpretação, resolver os casos difíceis. Essa atributividade seria determinada por regras jurídicas e por regras sociais, que podem ser anuladas quando confrontadas com alguma circunstância excepcional, pertencente a um rol impossível de ser taxativo. Nesse sentido:

\footnotetext{
A derrotabilidade (defeasibility) das normas jurídicas se refere à interpretação do Direito a partir das diferentes realidades fáticas e jurídicas, passando ao largo das questões de revogação ou derrogação, uma vez que não se pode desconsiderar sem a devida fundamentação o direito positivo (FROTA, 2010, p. 86).
}

A estrutura aberta do direito é inevitável diante da dificuldade inerente à complexidade humana e à linguagem, somada a impossibilidade de previsão de todas as especificidades casuísticas. 


\section{INTERRUPÇÃO DA GRAVIDEZ DE FETO ANENCÉFALO: APLICAÇÃO DO PRINCÍPIO DA DERROTABILIDADE DA NORMA PARA GARANTIA DO DIREITO À INTEGRIDADE PSÍQUICA DA PERSONALIDADE DA GESTANTE}

O silogismo jurídico é impresso na ideia de que uma premissa maior, universal e hipotética, tem determinada consequência normativa, levando a aplicação da lei ao fato concreto. No entanto, quando adicionada uma nova premissa ao conjunto inicial de premissas, a conclusão pode não ser a mesma. Ou seja, dependendo da premissa adicionada, ela pode 'derrotar' a conclusão inicial e acarretar em uma nova resposta.

A derrotabilidade é uma característica pertencente tanto ao Civil Law, qualificada por regras legislativas, quando do Commom Law, marcada pelas suas regra jurisprudenciais. Essa forma de interpretação aproxima ambos sistemas.

O sistema Commom Law é aquele adotado pelos países de origem anglo-saxônica, como Estados Unidos e Inglaterra, estruturado por meio de decisões dos tribunais, ou seja, o direito é caracterizado por sua formação baseada nos costumes e precedentes. O sistema Civil Law, adotado pelo Brasil, apoia-se fortemente no texto de lei para a formação do direito.

No Commom Law existem mecanismos de superação do precedente, momento em que decide-se pela não aplicação de uma regra jurisprudencial válida na teoria dos precedentes. São os chamados distinguish (distinção) e overruling (superação).

Tanto a utilização da derrotabilidade no sistema adotado pelo Brasil, quanto as formas de superação do sistema americano acima mencionado, realizam a mesma redução na aplicação das regras jurídicas, momento em que, diante do caso concreto, faz-se necessário a não aplicação do entendimento até então adotado, sob pena de incorrer em grave injustiça em decorrência da sua excessiva generalidade. Assim, ocorre uma retificação e diminuição do direito quanto ao seu âmbito de incidência, com o reconhecimento de uma exceção.

Entende-se que as regras de atribuição são abertas a revisões, visto que somente será aplicada quando nenhum vício for observado e quando não houver hipóteses de exceção por entender inaceitável o resultado.

Hart reconheceu primeiramente o caráter derrotável dos conceitos jurídicos. Posteriormente, defendeu o caráter derrotável das normas jurídicas, implicando na capacidade de existirem exceções implícitas sem que se perca a força normativa. Nesse sentido, Gavião Filho e Prevedello (2019a, p. 6) esclarecem sobre a derrotabilidade dos conceitos jurídicos:

Formulações gerais dos conceitos são úteis, mas insuficientes. É certo que elas podem servir para o desenvolvimento do direito, mas as condições nelas explicitadas não devem ser tomadas como necessárias e suficientes de modo universal para todos os casos. Fica aberta sempre a possibilidade de que novas circunstâncias possam fundamentar a não aplicabilidade dos conceitos e de suas consequências jurídicas. 
Nesse sentido, Hart afirma que os conceitos jurídicos não poderiam ser definidos por uma lista exaustiva de condições necessárias e suficientes. Os tribunais seriam os responsáveis pelo reconhecimento dessas exceções implícitas (impossíveis de serem listadas previamente) por meio da criação e desenvolvimento do direito.

Isso não significa que o direito é completamente indeterminado e aberto, nem que um supremo tribunal é o que diz o que é o direito. Faz-se necessário um padrão de decisões judiciais. Este padrão nunca é criado pelo judiciário. As regras apenas limitam e ao mesmo tempo permitem a atividade criadora dos juízes, cabendo aos operadores do direito tão somente manifestarem em manter ou delimitar a aplicação da norma.

Hart estaria propondo uma solução aos extremismos vindos das correntes de pensamento formalista e do realismo norte-americano, ao reconhecer a existência de exceções implícitas e consequente revogação ou derrogação de uma regra. Este fenômeno não implica na desvalorização da força normativa, que ainda vincula todos os demais casos não contaminados pela excepcionalidade. Em outras palavras, a regra permanece sendo integralmente aplicada.

A derrotabilidade adapta-se à Teoria dos Princípios do jurista alemão Robert Alexy, que é a concepção atualmente utilizada pelo Supremo Tribunal Federal para a solução dos casos difíceis, e à atual Constituição Federal, que é regida pelo modelo de regras e princípios. De acordo com essa teoria, as regras e os princípios são espécies das normas jurídicas.

As regras garantem direitos ou impõe deveres definitivos, ou seja, o direito deverá ser realizado totalmente, ainda que as regras suportem exceções. A regras válidas determinam a decisão a ser tomada de maneira obrigatória, devendo ser cumpridas de maneira exata por meio da aplicação integral ("tudo ou nada"). Sobre isso, Ávila esclarece acerca do valor das regras:

\begin{abstract}
A obediência das regras justifica-se não só na ideia de autoridade (devem ser seguidas porque são leis), mas porque pré-determinam escolhas que eliminam controvérsias e incertezas, afastam ou reduzem arbitrariedades passíveis de surgimento na aplicação de valores morais diretamente pelos julgadores, bem como evitam dificuldade de coordenação, deliberação e conhecimento entre as pessoas (ÁVILA, 2014, p. 140-141).
\end{abstract}

Em hipótese de conflito entre regras no caso concreto, uma das regras é declarada inválida ou é introduzida uma cláusula de exceção a uma delas: 
Estabelecido o conflito entre duas ou mais regras jurídicas, apenas uma delas pode ser declarada válida e pertencente ao ordenamento jurídico, pois o sistema jurídico não tolera a existência de regras jurídicas em oposição entre si (FARIAS, 2000, p. 119).

Para o jurista Richard Hart, a derrotabilidade seria uma característica exclusiva das regras jurídicas, seja legislativa ou jurisprudencial, tendo em vista que a técnica da subsunção é a que melhor dialoga com a derrotabilidade, pois a sua aplicação deve ser realizada de forma estrita, sem possibilidade de graduação da consequência jurídica.

As regras jurídicas, de aplicação geral para aqueles casos abstratamente considerados, são produto de ponderação previamente realizada pela autoridade normativa, estabelecendo as condutas a serem observadas e as consequências de sua violação. Neste momento, basta o intérprete aplicar via subsunção à regra ao caso sub judice ou excepcionar a regra jurídica válida. Nesta última hipótese, deparamo-nos com a aplicação do princípio da derrotabilidade.

Diferentemente das regras, os princípios não possuem pretensões de definitividade. Garantem direito e impõem deveres prima facie, o que significa que seriam realizados apenas parcialmente, pois haveria um caminho a ser percorrido entre o direito ou dever prima facie e aquilo que é garantido ou imposto de modo definitivo.

Os princípios devem ser realizados na maior medida possível e dentro das possibilidades jurídicas e fáticas do caso concreto. Assim, não se coadunam com a ideia de exceção, não havendo o que se falar em derrotabilidade dos princípios (GAVIÃO FILHO; PREVEDELLO, 2019, p. 12).

Os autores Jorge Luis Rodríguez e Germán Sucar (2005, p. 405-407) elegem onze principais "fatos geradores" da derrotabilidade em sua obra:

i. Alterações na interpretação de um mesmo enunciado jurídico como o transcurso do tempo;

ii. Introdução no sistema jurídico positivo de exceções antes não previstas;

iii. Interpretação sistemática de um enunciado jurídico no sentido de que seu conteúdo depende do exame de outros enunciados, os quais podem ensejar exceções à norma que vincule;

iv. Indeterminação do direito que decorre da textura aberta da linguagem e da dificuldade da adaptação de uma norma geral a um caso particular;

v. Impossibilidade de o legislador antever todas as circunstâncias fáticas em que a norma será aplicável, razão da possibilidade de se reconhecer exceções implícitas aos casos normais considerados por aquele;

vi. A função principal dos conceitos jurídicos não descritiva, mas sim atributiva de responsabilidade e de direitos, o que significa a inviabilidade de enquadrar os fatos em termos de condiçõos sempre necessárias e suficientes e a necessidade de reconhecer o caráter eminentemente derrotável de tais conceitos; 
vii. Qualquer norma jurídica pode ser derrotada quando um órgão jurisdicional reputa injusta a solução geral oferecida por colidir com valores morais positivados no sistema jurídico;

viii. A norma geral utilizada como fundamento de uma decisão_judicial serve não só para convalidar essa solução jurídica individual como também outras soluções igualmente válidas;

ix. Diferentes descrições de situações fáticas podem ensejar qualificações normativas também distintas, pois não se pode considerar como verdadeira ou completa uma descrição, ou seja, uma particularidade fática é capaz de tornar operativa uma exceção;

x. A informação acerca da realidade é sempre incompleta, motivo de os juízos proferidos serem derrotáveis à luz do surgimento de novas informações

xi. Pretensões judiciais podem ser superadas se a parte contrária demonstrar que concorre ao caso particular uma exceção prevista em alguma disposição do sistema jurídico.

Apesar de não ser possível ainda a conceituação e aplicação precisa do termo "derrotabilidade", todas as teses levantadas defendem um mesmo núcleo consequencial da afastabilidade da norma jurídica incompatível com a realidade fática do caso sub judice.

A solução justa para um determinado caso envolve não só a satisfação das partes envolvidas, mas também a valorização e reafirmação dos elementos básicos da condição humana. Deve conferir efetividade aos princípios constitucionais de ordem material ou imaterial, elevar os aspectos componentes de uma vida, o bem estar e o que a torna possível e sustentável.

\section{INTEGRIDADE PSÍQUICA COMO COMPONENTE DA PERSONALIDADE HUMANA}

A Constituição Federal brasileira vigente é chamada de Constituição cidadã, pois foi a partir dela que o homem passou a ser visto como o centro da sociedade, merecedor de respeito e proteção. Com base nessa valoração, os direitos fundamentais e os direitos da personalidade foram estruturados.

A concepção de dignidade da pessoa humana passou a ser o núcleo de vários movimentos jurídicos, e expressamente está previsto no artigo $5^{\circ}$, inciso, III, da Constituição Federal. A dignidade da pessoa humana é o princípio que justifica a incansável busca pela realização da justiça (SILVA; ZENNI, 2009, p. 203). Nesse sentido, esse princípio implica no mínimo necessário para a existência humana com observância à complexidade inerente do ser:

O princípio constitucional da dignidade da pessoa humana refere-se às exigências básicas do ser humano no sentido de que ao homem concreto sejam oferecidos os 
recursos de que dispõe a sociedade para a mantença de uma existência digna, bem como propiciadas as condições indispensáveis para o desenvolvimento de suas potencialidades (FARIAS, 2000, p. 63).

A Constituição Federal de 1988 não possui uma cláusula geral expressa reservada ao cuidado da personalidade, a exemplo de Constituição de outros países como a Constituição da Alemanha e da Itália (SZANIAWSKI, 2005, 136). O constituinte optou por inserir somente algumas categorias dos direitos da personalidade como: direito à vida, à igualdade, à intimidade, à vida privada, à honra, à imagem etc.

Embora haja uma taxatividade dos direitos da personalidade na Constituição Federal e no Código Civil (arts. 11-21), ocorre uma tendência para "generalizar-se" (MARINHO, 2000, p. 7). A tipificação lograda não pode impedir o reconhecimento de novos direitos da personalidade, sobretudo visto que "somos por um feixe natural de reivindicações axiológicas que constantemente nos convocam para aperfeiçoamento" (ZENNI, 2004, p. 8). Assim a teoria do direito geral da personalidade demonstra-se mais apropriada para garantir uma real proteção da pessoa e sua complexidade, "em última análise, da proteção jurídica da dignidade da pessoa humana” (BESSA; REIS, 2020, p. 8).

A personalidade é um atributo jurídico (GOMES, 2019) e pode ser conceituada como “o conjunto das qualidades e relações que determinam a pessoa em si mesma e em função da participação na ordem do ser, de forma única e singular" (GONÇALVES, 2008, p. 68).

Os direitos da personalidade são direitos inerentes à pessoa e a ela ligados de maneira perpétua e permanente (GONÇALVES, 2014, p. 184). São o conjunto de caracteres do próprio indivíduo que consiste na parte intrínseca da pessoa humana. É a partir desse direito, que as pessoas podem adquirir e defender os demais bens (SZANIAWSKI, 2005, 70). Assim, "compreendem-se direitos considerados essenciais à pessoa humana, que a doutrina moderna preconiza e disciplina, a fim de resguardar a sua dignidade" (GOMES, 2019).

Os direitos da personalidade devem ser dotados de elasticidade, ou seja, abrangente e com capacidade de proteção, já que limitar os direitos da personalidade àqueles expressamente tipificados contrariaria o próprio espírito da Constituição Federal de 1988 (BESSA; REIS, 2020, p. 11).

A doutrina reconhece que os direitos da personalidade são muito mais numerosos do que aqueles previstos em diplomas, tendo em vista que todas as normas jurídicas são também criadas no interesse dos indivíduos (CUPIS, 2004, p. 42). Verifica-se "a multiplicidade de direitos de personalidade aumentando a cada momento, de acordo com a evolução social, da 
tecnologia, da medicina e da biologia, provocaram um fracionamento dos direitos de personalidade" (SZANIAWSKI, 2005, p. 127).

Com o avanço das tecnologias e a evolução das sociedades, novos direitos são reivindicados. E é o caso da interrupção da gravidez de feto anencéfalo, que é abordado neste trabalho. O desenvolvimento da ciência permitiu a identificação da condição de anencefalia ainda em fase intrauterina, bem como possibilitou verificar a viabilidade de vida extrauterina.

O ordenamento jurídico brasileiro já estabeleceu previsões protetivas à inteireza mental da pessoa, como exemplo a possibilidade de dano moral nas responsabilizações civis e no penal o constrangimento ilegal (art. 146 do Código Penal) e cárcere privado com a imposição de sofrimento mental (art. 149 do Código Penal). Também, o constituinte tutelou a integridade psíquica quando vedou a tortura e o tratamento desumano e degradante (art. $5^{\circ}$, inciso III, CF) e a indenização do dano moral (art. $5^{\circ}$, inciso $\mathrm{X}, \mathrm{CF}$ ). Essas previsões demonstram o interesse do Estado em proteger o psicológico humano.

A proteção da saúde mental também encontra previsão em tratados e documentos internacionais, que igualmente debruçam-se a proteger a mente, como na Declaração sobre a proteção de todas as pessoas contra a tortura ou outros tratamentos ou penas cruéis, desumanos ou degradantes, de 1975.

O direito à incolumidade da mente e do psiquismo é um direito da personalidade vastamente reconhecido. A proteção jurídica da esfera psíquica da pessoa é defendida pelos antigos e novos doutrinadores:

Os atributos psíquicos do ser humano estão relacionados aos sentimentos de cada indivíduo. A própria noção de saúde passa pela higidez mental. A ideia de dignidade humana carrega em si um desejado equilíbrio psicológico. São ilícitas, portanto, as condutas que violam e afetam a integridade psíquica, que causam sentimentos negativos e desagradáveis, como tristeza, vergonha, constrangimento etc. (BESSA; REIS, 2020, p. 13).

A classificação da integridade psíquica como um direito da personalidade demonstra a importância dada às liberdades de convicções pessoais, políticas, religiosas, filosóficas e sociais de cada pessoa, o que o torna, por óbvio, humano.

$\mathrm{O}$ direito à integridade psíquica tem como objetivo preservar o conjunto psicoafetivo e pensante da estrutura humana, uma vez que a todos é imposto o dever de não afetar a estrutura psíquica de outrem (BITTAR, 2014, p. 182).

Assim como há o dever de abstenção para que ninguém fira tal direito, em circunstâncias pontuais, cabe ao Estado também ter ações positivas a fim evitar violações a 
direitos. A questão aqui analisada trata-se de um agir público para proteger direitos da gestante de grande valor no sistema jurídico.

Por isso é de se pensar que o Estado paternalista providente que distribui as chances da vida com igualdade absoluta corre o risco de prejudicar, mediante suas intervenções precipitadas, a autonomia que se propõe a tutelar. Da mesma sorte, como estrutura social mais perfeita, o Estado tem compromisso de interferir quando o indivíduo e os grupos menores não puderem atingir sponte própria os seus objetivos (ZENNI, 2004, p. 10).

No capítulo seguinte analisar-se-á a Arguição de Preceito Fundamental $n^{\circ}$ 54, que tratou da possibilidade de interrupção da gravidez de feto anencéfalo. Neste ponto, demonstrar-se-á a relação do direito à integridade psíquica como um dos motivos para aplicação da derrotabilidade na tipificação penal do crime de aborto.

\section{ARguiÇÃO DE PRECEITO FUNDAMENTAL No 54 E A POSSIBILIDAdE DE INTERRUPÇÃO DA GRAVIDEZ DE FETO ANENCÉFALO}

As questões da possibilidade de interrupção da gravidez ou o aborto, por qualquer justificativa, foi historicamente discutida e decidida na imensa maioria por pessoas do sexo masculino, pelo poder social dos homens. Tradicionalmente, o Congresso Nacional foi dominado por homens, conservadores e com forte presença religiosa. Esse predomínio, se não ainda presente, permaneceu por muitas décadas. A discussão do assunto nunca avançou. Houve quase que um impedimento ao debate.

Existe um debate acerca da nomenclatura apropriada para tratar o caso em questão. Enquanto alguns denominam de aborto por anencefalia, outros chamam de interrupção da gestação, assim como também antecipação terapêutica do parto.

A interrupção da gravidez de feto anencéfalo tratou-se de uma reivindicação por parte de mães submetidas a uma gestação completa, com os riscos inerentes à peculiaridade envolvida, e posterior nascimento de um bebê incompatível com a vida pós-natal e por poucas horas de vida extrauterina. O transcorrer de toda uma gestação resultava em grande frustração e dor, por vezes sabida meses antes, o que tornava ainda maior o sofrimento.

Já há tempo a anomalia é detectada pela ecografia: "exame realizado a partir do terceiro mês de gestação, permite a visualização da caixa craniana do feto, possibilitando o diagnóstico preciso da anencefalia, sem, entretanto, permitir qualquer tipo de cura ou perspectiva de sobrevida" (OLIVEIRA; MOTENEGRO; GARRAFA, 2005, p. 81-81). É pacífica a compreensão médica acerca da irreversibilidade da deformação, bem como a 
impossibilidade da vida extrauterina. Pelas técnicas científicas atuais, não há qualquer dúvida sobra a inviabilidade da vida humana.

Após anos, finalmente a questão foi decidida por meio da Arguição de Preceito Fundamental $\mathrm{n}^{\mathrm{o}}$ 54, em 2012. Conforme decisão proferida pelo Relator Ministro Marco Aurélio, julgou-se "procedente o pedido para declarar a inconstitucionalidade da interpretação segundo a qual a interrupção da gravidez de feto anencéfalo é conduta tipificada nos artigos 124, 126, 128, incisos I e II, todos do Código Penal” (BRASIL, 2012, p. 433). Veja-se a ementa:

\begin{abstract}
ADPF - ADEQUAÇÃO - INTERRUPÇÃO DA GRAVIDEZ - FETO ANENCÉFALO - POLÍTICA JUDICIÁRIA - MACROPROCESSO. Tanto quanto possível, há de ser dada sequiência a processo objetivo, chegando-se, de imediato, a pronunciamento do Supremo Tribunal Federal. Em jogo valores consagrados na Lei Fundamental - como o são os da dignidade da pessoa humana, da saúde, da liberdade e autonomia da manifestação da vontade e da legalidade -, considerados a interrupção da gravidez de feto anencéfalo e os enfoques diversificados sobre a configuração do crime de aborto, adequada surge a argüição de descumprimento de preceito fundamental. ADPF - LIMINAR - ANENCEFALIA INTERRUPÇÃO DA GRAVIDEZ - GLOSA PENAL - PROCESSOS EM CURSO - SUSPENSÃO. Pendente de julgamento a argüição de descumprimento de preceito fundamental, processos criminais em curso, em face da interrupção da gravidez no caso de anencefalia, devem ficar suspensos até o crivo final do Supremo Tribunal Federal. ADPF - LIMINAR - ANENCEFALIA INTERRUPÇÃO DA GRAVIDEZ - GLOSA PENAL - AFASTAMENTO MITIGAÇÃO. Na dicção da ilustrada maioria, entendimento em relação ao qual guardo reserva, não prevalece, em argüição de descumprimento de preceito fundamental, liminar no sentido de afastar a glosa penal relativamente àqueles que venham a participar da interrupção da gravidez no caso de anencefalia (BRASIL, 2012).
\end{abstract}

Vale lembrar que no Brasil é vedada a interrupção da gravidez, a menos que: a) para salvar a vida da gestante (art. 128, I, CP - Aborto necessário); e b) em caso de estupro (art. 128, II, CP). Após decisão da ADPF ora em análise, acrescentou-se uma terceira possibilidade: c) hipótese de o feto ser anencefálico.

Bitencourt afirma que a existência de causas excludentes de ilicitude para o crime de aborto, no Código Penal de 1940, demonstra que o legislador provavelmente incluiria o aborto anencefálico nas hipóteses de excludentes se houvesse na época o arsenal de conhecimento e tecnologia disponíveis nos dias de hoje (BITENCOURT, 2019, p. 436).

Após decisão, restou entendido que, ainda que a hipótese fática se enquadrasse perfeitamente na descrição hipotética contida nos artigos referente ao aborto, reconheceu-se a existência de uma exceção implícita à regra ao não aplicar a consequência jurídica quando 


\section{INTERRUPÇÃO DA GRAVIDEZ DE FETO ANENCÉFALO: APLICAÇÃO DO PRINCÍPIO DA DERROTABILIDADE DA NORMA PARA GARANTIA DO DIREITO À INTEGRIDADE PSÍQUICA DA PERSONALIDADE DA GESTANTE}

tratar-se de feto anencefálico. Por isso, a ADPF no 54 é um caso emblemático de aplicação do princípio da derrotabilidade.

A ADPF debruça-se na questão da responsabilidade penal dos médicos que realizam a interrupção da gravidez de feto anencéfalo, que teria aplicação dos artigos 124, 126, caput, e 128, incisos I e II, do Código Penal. O presente trabalho não se propõe a discutir pormenorizadamente as incidências penais, mas sim a discutir o direito da personalidade de integridade psíquica da gestante.

A decisão inicia-se pela a distinção entre as figuras da antecipação referida e o aborto, diante da diferença existente na potencialidade de vida extrauterina do feto. Os argumentos que envolvem a ação referem-se aos preceitos fundamentais como o princípio da dignidade da pessoa humana, a legalidade, a liberdade e autonomia da vontade e aqueles relacionados à saúde.

O bem jurídico protegido no crime de aborto, de acordo com a ampla doutrina, é a vida do ser humano em formação. Na hipótese ora examinada, resta prejudicada a hipótese fático-jurídica da tutela diante da ausência de vida viável em formação, visto que "somente o feto que apresente potencial capacidade de tornar-se pessoa pode ser sujeito passivo do crime de aborto" (BITENCOURT, 2019, p. 435). Logo, não haveria o que falar em aborto de feto anencéfalo, mas sim interrupção da gestação.

A prática médica demonstra que a permanência de um feto anômalo no útero da mãe é potencialmente perigoso à saúde e à integridade física e psíquica da gestante (BERALDI; DINIZ, 2007, p. 174). Assim, a gravidez anencefálica é potencialmente prejudicial, tanto fisicamente, quanto mentalmente para a gestante. Nesse sentido, a decisão proferida por Marco Aurélio, na ADPF $n^{\circ}$ 54, reconhece que esta situação causa danos reais no âmbito físico, moral e psicológico:

\footnotetext{
impor à mulher o dever de carregar por nove meses um feto que sabe, com plenitude de certeza, não sobreviverá, causa à gestante dor, angústia e frustração, resultando em violência às vertentes da dignidade humana - a física, a moral e a psicológica - e em cerceio à liberdade e autonomia da vontade, além de colocar em risco a saúde, tal como proclamada pela Organização Mundial da Saúde - o completo bem-estar físico, mental e social e não apenas a ausência de doença. (BRASIL, 2012)
}

Acerca dos impacto emocionais provocados na gestante, existe farta literatura que torna este fato inquestionável. Sobre isso, são impactantes as palavras da relatora desembargadora Giselda Leitão Teixeira, no Habeas Corpus n ${ }^{\circ} 84.025-6 /$ RJ, em que concedeu 
medida liminar autorizando a realização da intervenção cirúrgica destinada a promover a interrupção da gravidez:

$[\ldots]$

é justo condenar-se a mãe a meses de sofrimento, de angústia, de desespero, quando, desde logo, já se sabe que o feto está condenado de forma irremediável ao óbito, logo após o parto?

Não se trata de doença, mas de um embrião sem cérebro.

Desesperados, os pais vêm às portas do Judiciário buscar uma solução legal para o sofrimento eu sobre eles se abateu. Buscam a legalidade, o que demonstra nobreza de sentimentos e obediência à ordem jurídica vigente. Nada de agir às margens da lei, porque nada têm a esconder: tornam público ao drama que sobre eles se abateu e clamam por uma solução que ponha fim ao sofrimento e angústia.

$[\ldots]$

Não se pode impor à gestante o insuportável fardo de, ao longo de meses, prosseguir na gravidez já fadada ao insucesso. A morte do feto, logo após o parto, é inquestionável. Logo, infelizmente nada se pode fazer para salvar o ser em formação.

Assim, nossa preocupação deve ser para com o casal, em especial com a mãe, que padece de sérios problemas de ordem emocional ante o difícil momento porque passa.

A vida é um bem a ser preservado a qualquer custo, mas, quando a vida se torna inviável, não é justo condenar a mãe a meses de sofrimento, de angústia, de desespero. (BRASIL, 2004)

Embora muito sensível a postura da Desembargadora com a gestante e decidido pela autorização da interrupção da gravidez no supramencionado Habeas Corpus, ocorreram desdobramentos que resultaram na perda do objeto e consequente inocorrência da interrupção.

Nas palavras do Ministro Joaquim Barbosa "é possível imaginar a quantidade de sentimentos dolorosos por que passam aqueles que de súbito se vêem diante do dilema moral de interromper uma gestação, unicamente porque nada se pode fazer para salvar a vida do feto" (BRASIL, 2004, p. 11). Neste sentido:

No que tange à integridade psíquica da gestante, é imprescindível existir respeito à
situação de irremediável dor e sofrimento que a ela é infligida, por ter absoluta e
indiscutível certeza de que seu feto não sobreviverá. Assim como também se faz
necessário respeitar a autonomia e o livre arbítrio desta mulher, que profundamente
abalada pela constatação da malformação fetal incurável - já que não há
procedimento cirúrgico capaz de salvar este feto - decide interromper a gestação
(BERALDI; DINIZ, 2007, p. 175).

A vedação legal à interrupção da gravidez de uma gestante que traz "consigo durante nove meses um feto inviável, revela grave violação aos seus direitos de personalidade" (OLIVEIRA; MOTENEGRO; GARRAFA, 2005, p. 82). Há doutrinadores que entendem ocorrer tratamento desumano, vedado no inciso III, do artigo $5^{\circ}, \mathrm{CF}$, e não se poderia exigir 


\title{
INTERRUPÇÃO DA GRAVIDEZ DE FETO ANENCÉFALO: APLICAÇÃO DO PRINCÍPIO DA DERROTABILIDADE DA NORMA PARA GARANTIA DO DIREITO À INTEGRIDADE PSÍQUICA DA PERSONALIDADE DA GESTANTE
}

que a gestante levasse toda a sua gravidez sabendo da condição de anencefalia do feto (BITENCOURT, 2019, 442). Reafirma-se que esse dispositivo trata-se da cláusula geral de tutela da dignidade da pessoa humana.

\begin{abstract}
Apenas, se preferir, a gestante poderá aguardar o curso natural do ciclo biológico, mas, em contrapartida, não será "condenada" a abrigar dentro de si um tormento que a aniquila, brutaliza, desumaniza e destrói emocional e psicologicamente, visto que, ao contrário de outras gestantes que se preparam para dar à luz a vida, regozijandose com a beleza da repetição milenar da natureza, afoga-se na tristeza, no desgosto e na desilusão de ser condenada a - além da perda irreparável — continuar abrigando em seu ventre um ser inanimado, disforme e sem vida, aguardando o dia para, ao invés de brindar o nascimento do filho como todas as mães sonham, convidar os vizinhos para ajudá-la a enterrar um natimorto, que nunca teve chance alguma de nascer com vida (BITENCOURT, 2019, p. 434).
\end{abstract}

A interrupção da gravidez livre das amarras penais possibilita o resguardo da incolumidade física e psicológica daquela gestante que se vê em perigo e opta por essa via. $\mathrm{O}$ aborto como tipificado pressupõe a morte do feto causada pelo procedimento. No entanto, nos casos de anencefalia, não há o que se falar em vida viável em formação. Assim, há o esvaziamento do conteúdo material que fundamentaria a existência da norma protetiva diante da carência de suporte fático-jurídico. Logo, a antecipação consentida do parto de feto anencéfalo não afeta nenhum bem jurídico tutelado pelo crime de aborto (BITENCOURT, 2019, p. 435).

A interrupção da gestação de feto anencéfalo seria uma medida de caráter terapêutico para a gestante em risco. Conforme demonstrado, o risco não é apenas físico, mas também psicológico. A integridade psíquica da gestante que se depara com uma anomalia fetal incompatível com a vida deve ser sopesada na aplicação da justiça. Por isso, a derrotabilidade dos artigos penais referentes ao aborto tornou-se essencial para garantir a saúde e a segurança da mulher.

A discussão do problema em termos normativos restou inviável pelos fatores históricos e sociais, mas o próprio direito fornece instrumentos para a superação do entrave e para a garantia e efetividade dos direitos da personalidade. $\mathrm{O}$ reconhecimento dos anseios maternos por mecanismos jurídicos também compõem o regime democrático de direito.

\section{CONSIDERAÇÕES FINAIS}

Diante da velocidade em que os fatos jurídicos acontecem no mundo, bem como o constante surgimento de novas abordagens, a maleabilidade do sistema jurídico torna-se 
imprescindível. Ser aberto e dinâmico, permite que o direito acompanhe minimamente as exigências sociais no âmbito jurídico. A complexidade do mundo, das suas relações, da linguagem e da natureza humana impedem a previsão de todas as possibilidade de tutela pelo ordenamento. Não resta outra alternativa rápida e eficaz para a correta aplicação do direito e coerência com os princípios de justiça.

A excessiva generalização das previsões tuteladas pelo ordenamento jurídicos causa problemas quando da aplicação de regras gerais a casos particulares. O judiciário depara-se com situações de injustiças no momento de aplicação da regra, visto a violação de princípios. Está-se diante de um conflito entre princípios e regras.

A derrotabilidade é um instrumento, que se bem utilizado, pode trazer benefícios à sociedade. Uma importante característica das regras jurídicas quando aplicada a derrotabilidade é a sua capacidade de suportar exceções implícitas sem perder a força normativa. Ou seja, mesmo sendo passível de excepcionalidade a depender da situação fática, a norma continua a ter sua validade e total aplicação a todos os demais casos, não resultando ausência de regulação geral.

O reconhecimento da derrotabilidade das normas sobre o aborto nas hipóteses de feto anencéfalo demonstra uma solução adequada à gestante, que sofre riscos reais à própria vida e graves abalos psicológicos. A integridade psíquica pertence aos direitos da personalidade e é componente da saúde humana, e esta classificação não poderia ser diferente. O bem estar da mente é um dos aspectos mais importantes da vida humano. Não por menos as várias interferências jurídicas nessa esfera.

A ADPF n ${ }^{\circ} 54$ é uma demonstração da relação do estado de direito democrático e as reivindicações sociais. Depois de décadas sem serem ouvidas, e a passos lentos, mulheres passam a ter voz nas suas próprias questões. A derrotabilidade possibilitou manter o ordenamento jurídico compatível com a demanda histórica.

\section{REFERÊNCIAS}

ALEXY, Robert. Teoria dos direitos fundamentais. Tradução: Virgílo Afonso da Silva. São Paulo: Malheiros, 2008.

ÁVILA, Humberto. Teoria dos princípios: da definição à aplicação dos princípios jurídicos. 15. ed. São Paulo: Malheiros, 2014. 
BARALDI, Ivan Augusto; DINIZ, Nilza Maria. Reflexões sobre a interrupção da gestação de feto anencéfalo. Revista Brasileira de Bioética, v. 3, n. 2, p. 170-190, 2007. DOI:

10.26512/rbb.v3i2.7923. Disponível em: https://periodicos.unb.br/index.php/rbb/article/view. Acesso em: 24 mar. 2021.

BESSA, L. R.; REIS, M. P. P. Dano moral e dor: direito autônomo à integridade psíquica. civilistica.com, v. 9, n. 1, p. 1-17, 9 maio 2020.

BITENCOURT, Cezar Roberto. Código penal comentado. 10. ed. São Paulo: Saraiva, 2019.

BITTAR, Carlos Alberto. Os direitos da personalidade. 8. ed. São Paulo: Saraiva, 2014.

BRASIL. Constituição (1988). Constituição da República Federativa do Brasil. Brasília, DF: Senado Federal: Centro Gráfico, 1988.

Decreto-Lei $n^{0}$ 2.848, de 7 de dezembro de 1940. Código Penal. Brasília, DF:

Presidência da República, [1940]. Disponível em:

http://www.planalto.gov.br/ccivil_03/decreto-lei/del2848compilado.htm.

Lei $\mathbf{n}^{0}$ 6.259, de 30 de outubro de 1975. Dispõe sobre a organização das ações de Vigilância Epidemiológica, sobre o Programa Nacional de Imunizações, estabelece normas relativas à notificação compulsória de doenças, e dá outras providências. Brasília, DF:

Presidência da República. Disponível em:

http://www.planalto.gov.br/ccivil_03/leis/L6259.htm.

Lei $\mathbf{n}^{\circ}$ 10.406, de 10 de janeiro de 2002. Institui o Código Civil. Brasília, DF: Presidência da República, [2002]. Disponível em: http://www.planalto.gov.br/ccivil_03/leis/2002/110406.htm. Acesso em: 24 mar. 2021. Supremo Tribunal Federal. Arguição de Descumprimento de Preceito Fundamental 54 Distrito Federal. Relator: Min. Marco Aurélio. Decisão. Data de Julgamento: 12 de abril de 2012. Disponível em: https://jurisprudencia.stf.jus.br/pages/search/sjur229171/false. Acesso em: 24 mar. 2021. 
Supremo Tribunal Federal. Habeas Corpus n. 84.025 Rio de Janeiro. Relator: Min. Joaquim Barbosa. Decisão. Data de Julgamento: 04 de março de 2004. Disponível em: https://jurisprudencia.stf.jus.br/pages/search/sjur97348/false. Acesso em: 24 mar. 2021.

CUPIS, Adriano de. Os direitos da personalidade. Campinas: Romana, 2004.

FARIAS, Edilsom Pereira de. Colisão de direitos: a honra, a intimidade, a vida privada e a imagem versus a liberdade de expressão e informação. 2. ed. Porto Alegre: Sergio Antonio Fabris Editor, 2000.

FROTA, Pablo Malheiros da Cunha. Derrotabilidade das normas jurídicas e a sua aplicabilidade: o diálogo principiológico entre o direito contratual civil e o direito contratual administrativo. Revista da Faculdade de Direito UFPR, n. 52, p. 81-99, 2010.

GAVIÃO FILHO, Anizio Pires; PREVEDELLO, Alexandre. A derrotabilidade na teoria dos princípios. Revista Pensar, v. 24, n. 1, p. 1-14, 2019.

GAVIÃO FILHO, Anizio Pires; PREVEDELLO, Alexandre. A noção de derrotabilidade para Hebert L.A. Hart. Revista Direito GV, v. 15, n. 1, p. 1-21, 2019a.

GOMES, Orlando. Introdução ao direito civil. 22. ed. Rio de Janeiro: Forense, 2019.

GONÇALVES, Diogo Costa. Pessoas e direitos de personalidade: fundamentação ontológica da tutela. Almedina: São Paulo, 2008.

HART, H. L. A. The ascription of responsability and rights. Proceedings of the Aristotelian Society, n. 49, 1948-1949, p. 171-194.

MARINHO, Josaphat. O Projeto de novo Código Civil. Revista de informação legislativa, v. 37, n. 146, p. 5-13, abr./jun. 2000. Disponível em:

http://www2.senado.leg.br/bdsf/handle/id/576. Acesso em: 24 mar. 2021.

OLIVEIRA, Aline Albuquerque S. de; MONTENEGRO, Sandra; GARRAFA, Volnei.

Supremo Tribunal Federal do Brasil e o aborto do anencéfalo. Revista Bioética, v. 13, n. 1, p. 79-92, 2005. 


\section{INTERRUPÇÃO DA GRAVIDEZ DE FETO ANENCÉFALO: APLICAÇÃO DO PRINCÍPIO DA DERROTABILIDADE DA NORMA PARA GARANTIA DO DIREITO À INTEGRIDADE PSÍQUICA DA PERSONALIDADE DA GESTANTE}

SILVA, Elizabet Leal da. ZENNI, Alessandro Severino Vallér. Algumas considerações sobre o princípio da dignidade da pessoa humana. Revista Jurídica Cesumar, v. 9, n. 1, p. 201-222, 2009.

SZANIAWSKI, Elimar. Direitos de personalidade e sua tutela. RT: São Paulo, 2005.

ZENNI, Alessandro Severino Vallér. O retorno à metafísica como condição para concretização da dignidade da pessoa humana. Revista Jurídica Cesumar, v. 4, n. 1, p. 5-14, 2004. 